\title{
Investigation on Mechanical and Comfort Properties of Denim Woven Fabrics Made from Different Spandex Percentage for Sports Wear
}

\author{
Mesfin Shiferaw and Sampath VR* \\ Department of Textile Engineering, Bahirdar University, Ethiopiaa
}

Submission: March 05, 2021; Published: March 18, 2021

*Corresponding author: Sampath VR, Textile Engineering Department, Eitex, Salem Campus, Bahirdar University, Bahirdar, Ethiopia

\begin{abstract}
Denim is cotton and twill weave fabric that uses colored warp and white weft yarn and used for jeans, work clothes and casual wear considered as one of the most traditional and fashionable fabrics. In this study, stretchable denim fabrics for active sportswear was produced on Toyota ${ }^{\circledR}$ air jet loom with five different twill denim fabrics containing various percentages of elastane and the mechanical and comfort performance characteristics were studied. Different fabric constructions were woven by changing the amount of weft yarn Lycra percentage.3/1 twill denim produced fabric were used to conduct this work with the following particulars 64 EPI, 46 PPI, 10s Ne warp and 10s Ne weft yarn and fabric width $180 \mathrm{~cm}$..Vat (Sulfur) dyed cotton warp yarn and undyed weft yarn of $(10 \mathrm{sNe})$ for both warp and weft were used for producing denim fabrics. Weft yarn lycra percentage were changed up to five different values. A 98.5\%c/1.5 Lycra, $97.5 \% \mathrm{c} / 2.5 \%$ lycra, $96.5 \% \mathrm{c} / 3.5$ lycra, $95.5 \% \mathrm{c} / 4.5 \mathrm{lycra}$, and $94.5 \% \mathrm{c} / 5.5 \%$ for each fabric and their breaking strength, tear strength, abrasion resistance, breaking extension, air permeability, drape ability, stretch ability and pilling rate were assessed. The influence of various elastane percentages on the above denim fabric performance parameters are investigated by employing a one-way Analysis of Variance (ANOVA) statistical software package. This would help commercial stretch denim manufacturer to understand the effect of elastane percentage on fabric properties. The obtained results showed that Lycra proportion in the fabric has an effect on fabric tensile strength, tear strength, air permeability, stretch ability, pilling and drape ability. Tensile strength, tear strength and air permeability are higher at low elastane percentage while breaking elongation, drape ability, fabric stretch properties, abrasion and pilling are good at higher elastane percentage. The results were presented further ahead with comparing tables and charts.
\end{abstract}

Keywords: Denim fabrics; Lycra; Air permeability; Elastane yarn; Weaving

\section{Introduction}

Denim - one of the world's oldest fabrics - is most commonly associated with jeans. Today, denim jeans are one of the most popular clothing items, which are loved by many people around the globe regardless of the gender, culture, climate conditions, seasons, and social occasions. The birth of denim jeans is credited to the Bavarian-born businessman, Levi Strauss, who made his way to the Gold Rush in San Francisco nearly 150 years ago. Since then, the denim fabric has run the gamut from a basic work wear fabric to a fashion trend setter, it is one of the most fashionable items in the fashion and textile industry today and the original focus on durability and practicality has changed to fashion. The evolution of the denim market has led to the development of some unique and creative denim fabrics and opened new worlds of possibility for finishes. Deterioration in the denim fabric of the textile product is often important to the physical properties in deciding when the article has reached the end of it using life Mona MA [1].
Denim fabric is hard-wearing and has high density with a high mass per unit area and a 3/1 or 2/1-twill weaves construction. It is comfortable, fashionable, affordable, durable and a popular clothing material. Nowadays, the stretchable denims are in fashion due to its comfort fit and flexibility. These fabrics possess elasticity so that garments made out of stretchable denim fabric closely fit to body without restricting body movement. Clothes are mostly under strain in some parts of the body, such as the knee, elbow and lower back areas. Therefore, stretching is very important for the comfort of the wearer. Generally, fabrics are required to stretch comfortably in accordance with body movements, and also after -stretching, to retain their original shape without any deformation. However, if clothes don't have such great flexibility, deformation occurs which is dubbed as fabric bagging Ambedkar BR [2].The percentage of spandex used in the weaving industry depends on the fabric stretch required and fabric properties. Since the elasticity of these types varies up to $300 \%$, this is reflected on 
the final characteristics of knitted and woven fabrics Mona MA [1].

\section{Concept of product attributes}

In defining "comfort", it is evident that physiological and psychological factors play a significant role. These include a garment's thermal effect (e.g. warmth, breathability); sensory characteristics (e.g. tactile feeling/hand) and mobility (e.g. ease of movement). Fit can be defined as the conformance of a garment to an individual's body type or size Zhang [3]. According to Osmud Rahman [4] study, fit was the most significant and frequently mentioned attribute. The three major findings of Osmud are First, intrinsic cues (quality, style, color, comfort, fit and fabric) were relatively more important than extrinsic cues (price, brand name, and country-of-origin). Secondly, the fit attribute was ranked as the most significant cue for denim jeans consumption. And last, many product cues were strongly correlated, and they could provide multiple benefits and values to consumers.

\section{Elastane Fiber characteristics}

Elastane fibers, better known under their trade names such as Lycra, spandex and dorlastan, represent a further high point in the development of man-made fibres. Invented in 1937 in Germany, elastane has properties not found in nature, the most important having an extraordinary elasticity. Spandex is a generic term used to designate elastomeric fibres which have an extension-at-break greater than $200 \%$ and also show rapid recovery when tension is released. These fibres exhibit rubber like behavior with high reversible extension as high as $400-800$ $\%$. The name Spandex is an anagram of the word expands and is known as Elastane Senthilkumar M [5]. In general, spandex fibers are spun from polyurethane spinning solution. The spinning process is conducted using dry method by blowing hot air through the spun filaments with simultaneous evaporation of the solvent from them. The structure of elastic fibers is extracellular matrix macromolecules comprising an elastane core surrounded by a covering of fibrillin-rich micro fibrils. The structure of elastic fibers is complex because they have multiple components, tightly regulated developmental depositions, a multi-step hierarchical assembly and unique biochemical functions. In chemical terms, elastane is a synthetic linear macromolecule with a long chain containing at least $85 \%$ of segmented polyurethane along with the alternating hard and soft segments linked by urethane bonds - NH - CO - O -. Senthilkumar M [5].

\section{Techniques of merging cotton and spandex}

A core spun spandex yarn is a compound structure consisting of a spandex core surrounded by staple sheath fibers. The stretch in a core spun yarn is derived from the contraction of the elastomer from the extension to which it is subjected during textile mill spinning. There are many methods for merging spandex with other textile fibers, such as core spinning, rotor spinning, siro spinning, and air entangling. Core spinning is one of these methods, and can be applied by the ring, Murata vortex, friction spinning, and rotor twister techniques Mourad MM. Yet, to introduce various elastane's proportions for each yarn, the core's draft is modified as DuPont de Nemours [6] (Equation (1)):

$$
\begin{aligned}
\text { DElastane }= & \text { tElastane } \ldots \ldots \ldots \ldots \ldots . . . . . \\
& \text { TYarn } \times P
\end{aligned}
$$

Where D Elastane, T Yarn (tex), t Elastane (tex) and P (\%) are, elastane's draft, yarn's count, elastane count and fixed percentage of the elastane filament respectively.

\section{Construction and properties of denim fabric}

\section{Types of stretch denim fabrics}

There are two categories of stretchable denim fabrics, based on the degree of stretchability i.e. (a) power or action stretch and (b) comfort stretch. Power or action stretch provides a fabric with high degree of extensibility and quick recovery. The fabric stretch percentage generally ranges from at least $30 \%$ to $60 \%$ or more with no greater than $5 \%-6 \%$ recovery loss. Comfort stretch alludes to fabric with less than $30 \%$ stretch percentage and no greater than 2\% to 5\% recovery loss Ambedkar BR [2].

\section{Parameters affecting denim fabric}

Fabric construction and yarn densities play major role in determining fabric handle. Fabric weight is related with warp and weft densities in the fabric. So, variations in warp and weft densities and in the number of warp and weft yarns have significant effects on the handle characteristics of the fabrics. The ratio of warp threads/cm to weft threads/cm may result in increased yarn crimp, providing a potential increase in fabric extensibility in the warp direction. It was determined that small differences of technological parameters do not influence fabrics without elastane but have great influence on fabrics with elastane Ambedkar BR [2]. Fabric weight also influences the physical and elastic properties of denim fabrics for both- stretch and nonstretch fabrics under different finish type application. Flexural rigidity, breaking strength, breaking extension percentage and drape coefficient increases with increase in fabric weight for peach finished denim. At a fixed level of elastane content, the fabric stretches decreases as fabric weight increases, owing to the more inter yarn friction, whereas the fabric growth increases due to the less recovery of the fabric Choudhary AK, Sheena Bansa 2018.

Og ulata [7] studied the prediction of elongation properties of woven bi-stretch fabrics using ANN (artificial neural networks) and linear regression methods. This study demonstrated that, regarding the prediction of elongation properties, both methods showed high predicting power. Investigated the bagging deformation of elastic woven fabrics for different numbers of cyclic loads, levels of draw ratio of the elastane core in the yarn and twist factor of the yarn. It was determined that the decrease in draw ratio and increase in twist coefficient of core spun yarns lead to a decrease in elastic recovery. Also, the number of cyclic loads was found to be significant on bagging deformation up to 1000 
cycles Baghaeia [8]. Das A \& Chakraborty R [9] studied that the increase in yarn twist multiplayer results in consistent increase in breaking load of fabric, but with the increase in elastane stretch the breaking load of fabric reduces. With the increase in the amount of twist the shear rigidity of fabric increases and the increase in elastane stretch results in consistent reduction in shear rigidity of fabric. The increase in proportion of elastane core decreases the shear rigidity of fabric. The increase in yarn twist, in general, results in increase in shear hysteresis, whereas the shear hysteresis of fabrics decreases with the increase in elastane stretch.

The increase in the level of yarn twist increases the bending rigidity of fabrics, whereas the increase in elastane stretch reduces the bending rigidity of fabrics. The proportion of elastane core does not have any significant on the bending rigidity of fabrics. Muhammad Bilal Qadir [10] studied the effect of elastane denier and draft ratio fabric on mechanical properties. Conclude that using a higher denier elastane in the core-spun cotton yarn, the fabric tear strength, stretch ability and recovery after stretch increases but the fabric tensile strength decreases. Furthermore, by increasing the elastane draft ratio, the fabric tensile strength and stretch ability increases whereas the fabric tear strength and recovery after stretch decreases. In weaving stretch fabrics, the type and degree of adjustment required depends upon whether we are dealing with filling or warp direction stretch. In filling stretch fabrics, warp preparation is normal except that adequate adjustments must be made in loom sley to allow for fabric contraction which takes place between the reed width and finished width. The main precaution required in weaving of filling stretch fabrics involves tension controls on the filling yarns during pick insertion. Tension must be adequate to extend the yarn to the point where its stiffness increases markedly, that is, to the limit of straightening of sheath fibers. This provides maximum stretch and also insures fabric uniformity Ibrahim SM [11].

Table 3: Yarn properties.

\begin{tabular}{|c|c|c|c|c|c|c|c|c|c|}
\hline $\begin{array}{c}\text { Yarn } \\
\text { Sample }\end{array}$ & $\begin{array}{l}\text { Breaking } \\
\text { Strength, } \\
\text { (cN/tex) }\end{array}$ & $\begin{array}{c}\text { Breaking } \\
\text { Elongation, } \\
(\%)\end{array}$ & U\% & $\begin{array}{l}\text { Unevenness, } \\
\text { (CVm\%) }\end{array}$ & $\begin{array}{l}\text { Thin Places, } \\
(-50 \% / \mathrm{km})\end{array}$ & $\begin{array}{l}\text { Thick Places, } \\
\text { (+50\%/km) }\end{array}$ & $\begin{array}{c}\text { Neps, } \\
(+200 \% / \\
\text { km) }\end{array}$ & 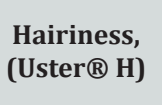 & Sh \\
\hline \multicolumn{10}{|c|}{ Warp yarn } \\
\hline & 13.64 & 7.68 & 8.95 & 11.26 & 0 & 5 & 0 & 5.12 & 1.06 \\
\hline \multicolumn{10}{|c|}{ Weft yarn } \\
\hline $\mathrm{C} 1$ & 13.55 & 8.84 & 8.85 & 11.21 & 0 & 13.8 & 12.5 & 8.2 & 1.95 \\
\hline $\mathrm{C} 2$ & 13.84 & 9.22 & 9.76 & 12.37 & 0 & 40 & 30.6 & 8.66 & 1.99 \\
\hline $\mathrm{C} 3$ & 13.22 & 9.45 & 8.66 & 10.99 & 1.3 & 70 & 65 & 7.47 & 1.83 \\
\hline $\mathrm{C} 4$ & 12.79 & 10.32 & 8.99 & 10.23 & 0.5 & 45 & 60 & 8.1 & 1.92 \\
\hline $\mathrm{C} 5$ & 11.83 & 10.64 & 8.52 & 10.21 & 2.5 & 25 & 40 & 7.12 & 1.72 \\
\hline
\end{tabular}

\section{Methods}

In this study, five different cotton denim fabric samples with $3 / 1$ twill structure having different amounts of spandex

\section{Materials and Methods}

\section{Materials}

The Toyota ${ }^{\circledR}$ air jet looms are used to produce a 3/1 warp faced fabric made from dyed warp yarn and undyed weft yarn. A $98.5 \%$ c/1.5 Lycra, 97.5\%c/2.5\%lycra, 96.5\%c/3.5lycra, 95.5\%c/4.5lycra, and $94.5 \%$ c/5.5\%lycra $3 / 1$ twill denim produced fabric were used to conduct this work with the following particulars 64 EPI, 46 PPI, 10s Ne warp and 10s Ne weft yarn and fabric width $180 \mathrm{~cm}$. Weft yarns were produced from modified ring spinning system using elastane fibers of 70Dtex at five spandex percentage level 1.5, 2.5, 3.5, 4.5 and 5.5 as a filament and sheath consists of staple cotton fibers (Table 1-3).

Table 1: Warp Specifications.

\begin{tabular}{|c|c|}
\hline Parameters & Specifications \\
\hline Yarn count & $10 \mathrm{Ne}$ \\
\hline Yarn type & $100 \%$ cotton (rotor) \\
\hline Yarn appearance & Even / normal \\
\hline Yarn status & Dyed \\
\hline Dye type & Vat (sulfur) \\
\hline Ends per width & 4608 \\
\hline
\end{tabular}

Table 2: Weft yarn production specifications.

\begin{tabular}{|c|c|}
\hline Parameters & Specification \\
\hline Lycra yarn count & 70 Dtex \\
\hline Lycra draft & $2.15-6.2$ \\
\hline Roving cotton draft & 1.16 \\
\hline Yarn appearance & Normal/ even \\
\hline Yarn status & White \\
\hline Yarn type & Core spun yarn \\
\hline
\end{tabular}

percentage were woven to investigate its mechanical and comfort properties. The fabric samples were woven on air jet weaving machine and with specific insertion rate. Weft - core yarns with 
different spandex rates were used and the layout of the weft yarns in the fabric structure. The fabric samples were code as C1, C2, C3, C4 and C5 with different percentage of Lycra 1.5\%, 2.5\%, 3.5\%, $4.5 \%$, and $5.5 \%$ respectively. Regarding the test results the effects of varying spandex percentage on the mechanical and comfort properties were assessed and analyzed for significant difference in means via SPSS statistical package.

\section{Yarn manufacturing and testing methods}

$100 \%$ cotton even warp yarns of $10 \mathrm{Ne}$ were manufactured using rotor spinning system while the $10 \mathrm{Ne}$ weft yarns were produced by making $100 \%$ cotton roving as sheath material and elastane as a core material for all yarn types. Weft Yarn samples were spun in the same yarn count and twist coefficient on WF 288 spandex covering machine, modified ring spinning frame with special equipment. The percentage variation on weft yarn manufacturing done by varying the draft ratio of the elastane material but other spinning parameters such as spindle speed were kept constant. The elastane and drafted staple fibers are brought together at the nip point of front rollers of the drafting unit. The elastane thread is stretched between the positive feed roller and the front rollers of the drafting unit. Yarns were tested and evaluated for important mechanical and comfort properties such as, imperfections, tenacity, breaking elongation, hairiness, neps, short fiber and yarn evenness. Yarn uniformity, thin, thick, IPI values and yarn hairiness were measured on Uster Tester 5, tensile properties were measured with premier tensomaxx. Test results are given in Table 3.

\section{Fabric manufacturing method}

Warp yarns were processed in conventional denim process, which includes rope dyeing, rope opening (LCB), sizing etc. corespun yarns were used as weft yarns in weaving. The weaving process was performed in Toyota air jet loom with five different elastane percentage values and the other production parameters were kept constant. Z Twill 3/1 woven fabrics were treated according to standard denim finishing procedures.

\section{Methods for quality testing}

Denim fabric sample tests were performed after conditioning the samples in the standard testing atmosphere $65 \%$ Relative Humidity and temperature $20 \pm 2{ }^{\circ} \mathrm{C}$ Temperature. Fabric properties which are tested are tensile strength, tear strength, fabric extension, Abrasion resistance, drape ability, pilling, stretch ability and air permeability. Fabric tests, instruments, and test standards are summarized in Table 4.

Table 4: Parameters, testing methods and equipment's.

\begin{tabular}{|c|c|c|c|}
\hline No & Fabric Parameters & Method & Equipment \\
\hline 1 & Drape ability & Es ISO 9073 & Cusic drape tester \\
\hline 2 & Tensile strength and extension & ASTM D 5035-11 & Universal tensile tester \\
\hline 3 & Tear strength & ASTM D 1424-09 & Flmendorf tear tester \\
\hline 4 & Stretchable properties & ASTM D 3107-07 & Martindale abrasion tester \\
\hline 5 & Abrasion resistance & ASTM D 4966 & Air Permeability Tester \\
\hline 6 & Air permeability & ASTM D 737 & Martindale pilling Tester \\
\hline 7 & Determination of pill rating & ASTM D 4970 & \\
\hline
\end{tabular}

\section{i. Drape ability}

Drape property of denim fabric is measured from the deformation by gravitational force of an initially horizontal fabric cut in the form of an annular ring using ISO 13937. A circular fabric specimen is held concentrically between smaller horizontal disc and the lower supporting disc. Fabric is allowed to drape into graceful folds around the lower supporting disc. The outline of shadow is traced on paper and then its mass is determined. Initially, the weight of paper of $30 \mathrm{~cm}$ dia is determined and the drape co-efficient is calculated. Drape coefficient (F) is defined as the fraction of the area of the annular ring between the flat fabric edge and the supporting disc edge covered by the projection of the draped sample \& given as.

$$
\begin{aligned}
& \text { Drape Coefficient, } F(\%)=\frac{(\text { Area under Drape Specimen }- \text { Area of disc })}{(\text { Area of Specimen }- \text { Area of disc })} \\
& \times 100 \frac{(W 2-W 3)}{(W 1-W 3)} \times 100
\end{aligned}
$$

\section{ii. Tensile strength and extension}

The fabric tensile strength and extension values were measured according to standard ASTM D5035-11 [12] standard strip for denim woven fabrics. The experiments were performed with a Tenso lab tensile strength tester, the distance between the jaws is $3 \mathrm{inch}$, and the speed of the universal tensile strength tester was $300 \mathrm{~mm} / \mathrm{min}$. Tests were performed in warp and weft directions and five samples are taken from both directions of each type of fabric. The length of sample for test (specimen) is 4-inch width by 6 -inch length with pretension of $1 \%$, clamp speed of test $=300 \mathrm{~mm} / \mathrm{min}$.

\section{iii. Fabric tear strength}

The tearing strength of the fabric was measured according to ASTM D 1424-9 [13] Standard Test Method used for Tearing Strength. It uses pendulum to apply energy sufficient to tear through a fixed length of fabric. In this experiment the tear 
strength of the cotton denim twill fabric was determined by using pendulum Elmendorf tearing strength Apparatus (Origin Germany) and the sample size used is (template) $7.5 \mathrm{~cm} \times 10 \mathrm{~cm}$. A sharp knife is used to begin the tear of the test specimen by cutting a slit of $20 \mathrm{~mm}$ mid-way between two jaws. The mean tear force across warp and weft were calculated. Test load D was used the tests.

\section{iv. Stretchable properties}

Fabric stretch-ability properties are related with fabric stretching percentage, fabric growth percentage and elastic recovery percentage. Fabric stretch-ability properties are tested as per ASTM standard D3107-07 [14]. The sample of $65 \mathrm{~mm} \times 560 \mathrm{~mm}$ was cut from fabric. Elastic performance is the ability of a material to exhibit its original properties after repeated use under cyclic loading and unloading, so fabric stretchable properties after cycling loading were also measured. Cyclic loading was done at three different target loads, i.e. 35\% Breaking Load, 55\% Breaking Load \& 75\% Breaking Load, and then fabric stretching (eq. i), fabric growth (eq. ii) and elastic recovery (eq. iii) values were calculated.

$$
\begin{aligned}
& \text { Fabric stretching }(\%)=100 x(B-A) / A \ldots \ldots \ldots \ldots \ldots \ldots \ldots \ldots \ldots \ldots \\
& \text { Fabric growth }(\%)=100 x(C-A) / A \\
& \text { Elastic recovery }(\%)=100 x(B-C) /(B-A) \text {....... }
\end{aligned}
$$

Where, A- The distance marked between the upper and bottom parts of the fabric $(250 \mathrm{~mm})$,

B- The distance between the marked points after 10 cycles of loading (in 'mm') \&

C- The distance between the marked points after 1-hour relaxation.

\section{v. Abrasion resistance}

The Abrasion resistance tests were performed according to ASTM D 4966 [15], determination of abrasion resistance of fabrics by Martindale method. The sample fabric is rubbed against a standard woolen abrasion fabric using a standard testing load $9 \mathrm{kpa}$ with a revolution of 5000 . Specimens are circular of $38 \mathrm{~mm}$ in diameter. The small test specimen is sitting on the large abradant (The dimension of the abradant shall be at $140 \mathrm{~mm}$ in diameter) and then cycled backwards and forwards in motion producing even wear. The colour change and appearance of the specimen was also evaluated after every test interval by comparing with the standard photographic film and tested samples were rated from 1 to 5 , as 5 is the best with less no abrasion and 1 is the worse with very severe abrasion.

\section{vi. Air permeability}

Air permeability is the measure of the rate of air flow passing perpendicularly through a known area under a prescribed air pressure differential between the two surfaces of a material of textile fabrics. Air permeability is an important factor in the performance of denim apparels. It depends on many factors such as weave structure, fabric thickness, weight and porosity. Fabric air permeability tests were performed on machine model FX 3300 as per ASTM D737 [16] standard. Total five readings were taken from each fabric. Read and record the individual test results in SI units as $\mathrm{cm}^{3} / \mathrm{cm}^{2} / \mathrm{s}$ [17].

\section{vii. Determination of pill rating}

This test was carried out by using Martindale Pilling and Abrasion Tester. The pilling test was achieved according to ASTM D 4970 [18]. The evaluation of the pilling of tested samples was assessed subjectively after 5000 revolutions with a test load of 9Kpa by comparing them with a standard photographic film and tested samples was rated from 1 to 5 , as 5 is the best with less pilling and 1 is the worse with more pilling.

\section{Statistical Analysis}

To determine the relationship between independent variables (elastane percentage) and the response variables (tensile strength, breaking extension, tear strength, air permeability, fabric stretch ability, drape ability, pilling resistant and abrasion resistance) the one-way Analysis of Variance (ANOVA) statistical software package were used to analyze the tested results of all the samples by comparison the significance value of fabric properties.

\section{Result and Discussion}

Assessments of the produced fabrics for mechanical and comfort properties were carried out in both the warp and weft direction for each of selected fabric characteristics.

\section{Effect on fabric mechanical properties}

In this study mechanical properties include Tensile Strength $(\mathrm{N})$, Tear strength $(\mathrm{N})$ and Breaking Extension (\%) were analyzed for denim fabric made from different spandex percentage. The test results for mechanical properties of Denim samples are given in Tables.

\section{Fabric tensile strength}

Table 5 The tensile strength of a fabric is a measure of its performance during use. The fabric used for the construction of particular clothing should be able to withstand the fatigue applied to it. A garment with insufficient tensile strength may fail during use, which can lead to the rejection of the garment. The effect of spandex percentage on tensile strength in the direction of both warp and weft are shown in Figure 1. According to the statistical analysis from the ANOVA Table 5, the fabric tensile strength were affected significantly at significance level 0.00 by the percentage of spandex in both warp and weft direction but change in warp direction is not such much significant as compared to the weft direction. Figure 1 shows the values of woven fabric tensile strength versus spandex percentage and reveals that as the amount of spandex increases, the tensile strength of the woven 
fabrics decreases in warp as wheel as weft direction. This is due to the lower tenacity of spandex fibers compared to cotton fibers (Figure 1). The statistical analysis showed that the maximum tensile strength was associated with the fabric sample C1 and the minimum value of tensile strength was observed for the sample
C5. From statistical analysis (one-way ANOVA) it was observed that there is a significant difference in the tensile strength of the five experimental fabrics having different spandex percentage in both warp $(F=14.222, p=0.000)$ and weft $(F=66.158, p=0.000)$.

Table 5: ANOVA table for tensile strength.

\begin{tabular}{|c|c|c|c|c|c|c|}
\hline \multirow{3}{*}{ Between Groups } & Direction & Sum of Squares & Df & Mean Square & F & 14.222 \\
& Warp & 82327.84 & 4 & 20581.96 & 66.158 \\
& weft & 80093.36 & 4 & 66.158 & 0 \\
\multirow{3}{*}{ Within Groups } & Warp & 28943.6 & 20 & 1447.18 & \\
& Weft & 6053.2 & 20 & 302.66 & \\
\hline
\end{tabular}

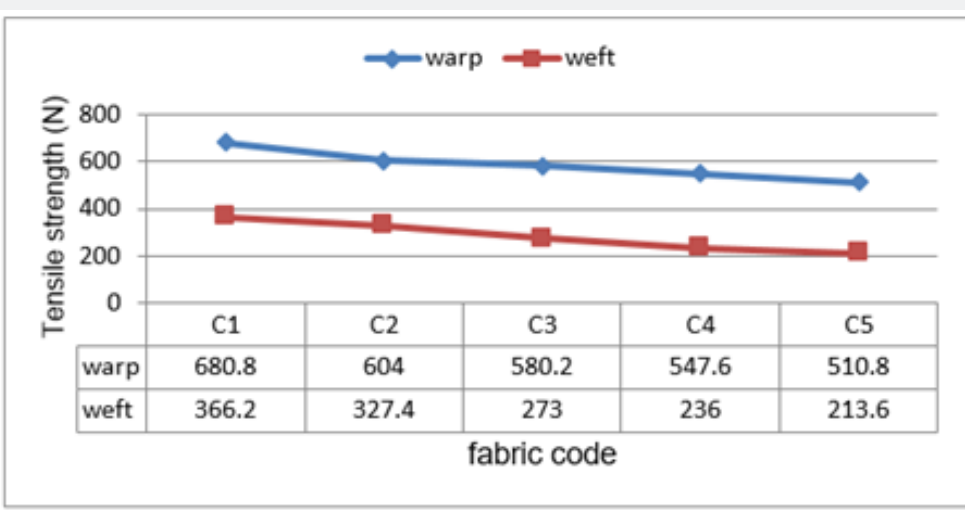

Figure 1: Tensile strength of denim fabrics at different spandex percentage.

\section{Breaking elongation}

Table 6 Breaking elongation of different fabric samples were investigated via different spandex percentage. The statistical analysis proved that the breaking elongations of fabric samples were significantly affected by the percentage of spandex at significance level $\mathrm{P}=0.000$ in weft direction but in warp direction breaking elongation is not influenced by spandex percentage since the significance level is $\mathrm{P}=0.237$. As seen from Figure 2 , the fabric breaking elongation increases with the increase in spandex content along the weft but the change in warp direction is not such significant. This is because the breaking elongation of spandex fibers $(500 \%)$ was higher than that of cotton fibers $(7 \%)$. That maximum breaking elongation of $64.4 \%$ was observed for fabric sample $\mathrm{C} 5$ and the minimum value of breaking elongation $33 \%$ was also observed for the fabric sample C1 (Figure 2).

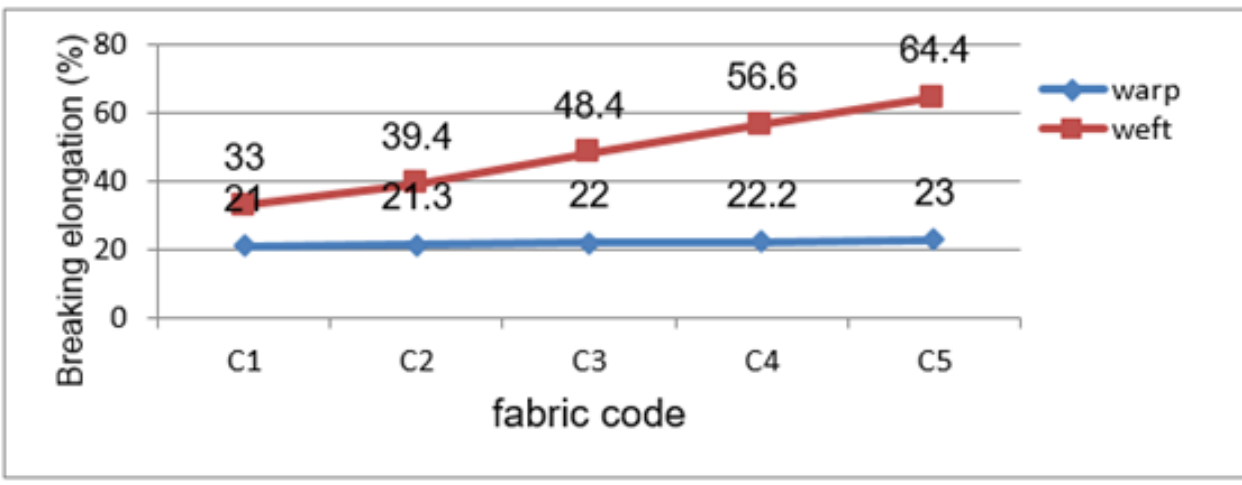

Figure 2: Breaking elongation of denim fabrics at different spandex percentage. 


\section{Tearing strength}

Table 7 Tear strength of woven fabrics is mainly related to its service ability. From the statistical analysis of tear strength, it is clearly seen that fabric tear strength significantly affected by the percentage of spandex in weft yarns. In this study spandex percentage versus tear strength were plotted in Figure 3 and observed that there is a negative relationship between tearing strength and spandex percentage. As the spandex percentage increases the fabric tearing strength decreases. This is because the lower fabric weight and relatively loose fabrics are always accompanied by lower spandex rate (Figure 3).

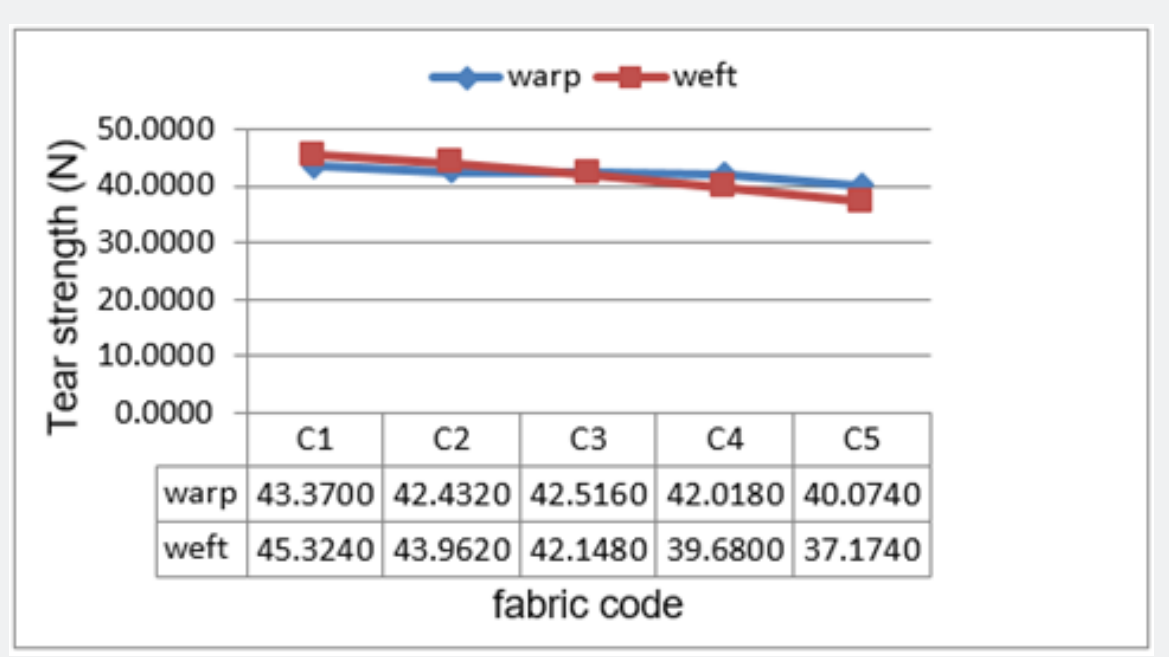

Figure 3: Tear strength of denim fabrics at different spandex percentage.

Table 6: ANOVA table for breaking elongation.

\begin{tabular}{|c|c|c|c|c|c|c|}
\hline & Direction & Sum of Squares & Df & Mean Square & F & Sig. \\
\hline \multirow{2}{*}{ Between Groups } & Warp & 12.762 & 4 & 3.19 & 1.512 & 0.237 \\
\cline { 2 - 7 } & Weft & 3208.455 & 4 & 802.114 & 48.87 & 0 \\
\hline \multirow{2}{*}{ Within Groups } & Warp & 42.213 & 20 & 2.111 & & \\
\cline { 2 - 7 } & Weft & 328.266 & 20 & 16.413 & & \\
\hline
\end{tabular}

\section{Influences on fabric comfort parameters}

Fabric comfort parameters include air permeability and drape coefficient of the fabric.

\section{Air permeability}

Table 8 Analysis of variance (ANOVA) was performed to determine the statistical significance of the effects of elastane percentage on fabric air permeability. The Air permeability performance of those samples with different stretchable fabrics was illustrated in Figure 4 and observed that the Lycra percentage has a profound effect on fabric air permeability. As the percentage of spandex in weft yarns increases, the air permeability decreases. The statistical analysis proved that the maximum air permeability was associated with the fabric sample C1, while the lowest air permeability was noticed for the sample C5. The higher value of air permeability is observed in the fabric with lower value of Lycra percentage and it decreased as the Lycra percentages were increased. As Lycra percentage increased in the fabric, contraction, of the woven fabric were more, which made the fabric more compact, bulk and thicker, resulting in higher resistance to air flow. Hence, the higher amount of Lycra content can help in achieving higher stretch ability, with reduced air permeability. From statistical analysis it was observed that there is a significant difference in fabric air permeability of the five denim fabrics having different Lycra content $(F=94.675, p=0.000$ ) (Figure 4).

\section{Drape ability}

Table 9 Fabric drape is a measure of the fabric stiffness. A fabric with higher drape coefficient will be stiffer. The stiffness affects the fabric drape and tactile comfort. The fabric with very low drape ability is not comfortable to wear and cannot bend as per the body contours. The effect of Lycra percentage on fabric drape of the stretchable denim fabric is shown in Figure 5 and observed that as the percentage of elastane increases the drape coefficient of the denim fabric decreases meaning that fabric drape ability 
becomes good. From statistical analysis (one-way ANOVA) it can be observed that there is a significant difference between the fabric drape ability of the denim fabric samples having different Lycra percentage $(\mathrm{F}=98.826, \mathrm{p}=0.000)$ (Figure 5).

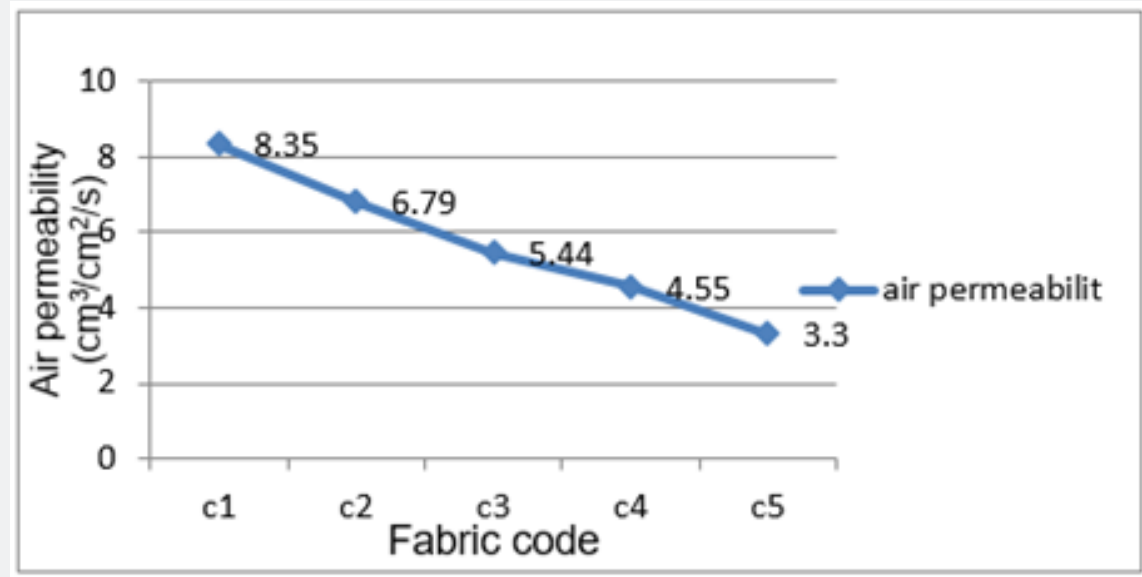

Figure 4: Air permeability of denim fabrics at different spandex percentage.

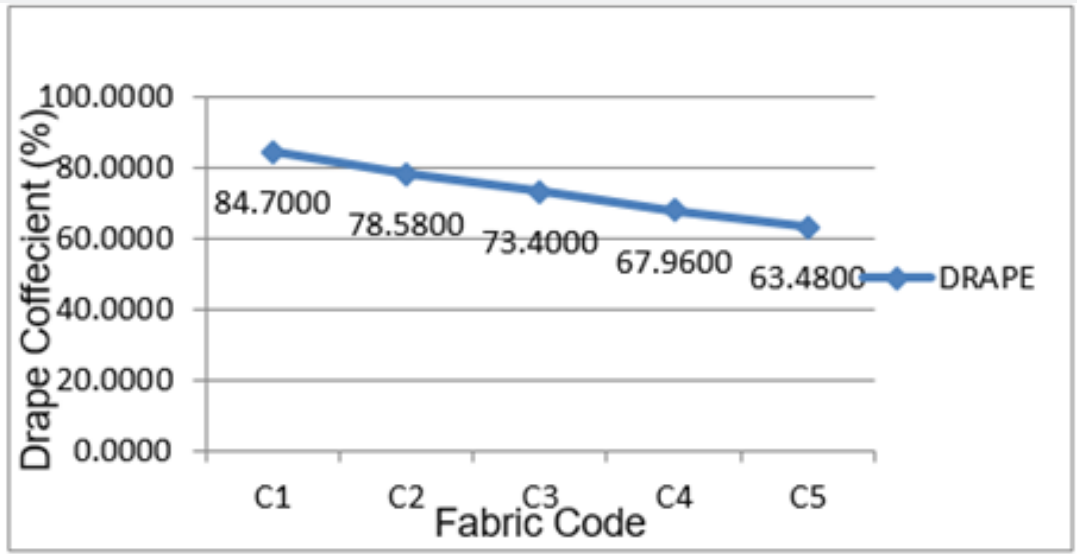

Figure 5: Drape ability of denim fabrics at different spandex percentage.

Table 7: ANOVA table for tear strength

\begin{tabular}{|c|c|c|c|c|c|c|}
\hline & Direction & Sum of Squares & Df & Mean Square & F & Sig. \\
\hline \multirow{2}{*}{ Between Groups } & Warp & 30.03 & 4 & 7.507 & 1.915 & 0.147 \\
\cline { 2 - 7 } & Weft & 215.034 & 4 & 53.759 & 9.015 & 0 \\
\hline \multirow{2}{*}{ Within Groups } & Warp & 78.423 & 20 & 3.921 & \\
\cline { 2 - 7 } & Weft & 119.271 & 20 & 5.964 & & \\
\hline
\end{tabular}

.Table 8: ANOVA table for air permeability.

\begin{tabular}{|c|c|c|c|c|c|}
\hline & Sum of Squares & Df & Mean Square & F & Sig. \\
\hline Between Groups & 76.903 & 4 & 19.226 & 94.675 & 0 \\
\hline Within Groups & 4.061 & 20 & 0.203 & & \\
\hline Total & 80.965 & 24 & & & \\
\hline
\end{tabular}


Table 9: ANOVA table for drape ability.

\begin{tabular}{|c|c|c|c|c|c|}
\hline & Sum of Squares & df & Mean Square & F & Sig. \\
\hline Between Groups & 1420.244 & 4 & 355.061 & 98.826 & \\
\hline Within Groups & 71.856 & 20 & 3.593 & & \\
\hline Total & 1492.1 & 24 & & \\
\hline
\end{tabular}

\section{Influences on fabric stretchable properties}

The test results for Fabric Stretch, Fabric Growth and Elastic Recovery of Denim samples are given in Table 10. The effect on stretchable properties is analyzed under different loading (30N, $45 \mathrm{~N}, 60 \mathrm{~N}$ ) of each sample fabric. Test results for fabric Stretch (\%), Fabric Growth (\%) and Elastic Recovery \% were calculated and given on the table below Table 10.

Table 10: Fabric Stretch, Fabric Growth and Elastic Recovery properties of fabric samples.

\begin{tabular}{|c|c|c|c|c|c|c|c|c|c|}
\hline \multirow[t]{2}{*}{ Fabric Code } & \multicolumn{9}{|c|}{ Breaking load (N) } \\
\hline & 30 & 45 & 60 & 30 & 45 & 60 & 30 & 45 & 60 \\
\hline & \multicolumn{3}{|c|}{ Fabric Stretch } & \multicolumn{3}{|c|}{ fabric growth } & \multicolumn{3}{|c|}{ Elastic Recovery } \\
\hline $\mathrm{C} 1$ & 5.272 & 7.462 & 7.286 & 3.51 & 3.84 & 4.73 & 75.49 & 73.43 & 73.4 \\
\hline $\mathrm{C} 2$ & 8.344 & 9.481 & 10.21 & 2.98 & 3.59 & 3.9 & 78.72 & 74.42 & 72.88 \\
\hline $\mathrm{C} 3$ & 10.11 & 11.02 & 12.5 & 2.44 & 2.73 & 2.87 & 83.73 & 82.08 & 79.61 \\
\hline $\mathrm{C} 4$ & 13.48 & 15.12 & 18.02 & 2.06 & 2.58 & 2.87 & 88.63 & 83.84 & 80.49 \\
\hline C5 & 19.46 & 22.85 & 25.79 & 1.52 & 1.95 & 2.28 & 96.84 & 95.15 & 91.34 \\
\hline
\end{tabular}

\section{Fabric Stretch}

Table 11 Fabric stretch ability indicates the property of the fabric that facilitates the body part movements. A fabric with higher stretch may follow the body movement easily. However, once the force is being removed, the fabric should return to its original dimensions. The fabric containing Lycra are well known for their good stretch ability and stretch recovery characteristics. The interactive relation between spandex percentage and fabric stretch ability of denim fabrics are shown in Figure 6. It can be observed that the stretch ability was increased with the Lycra percentage since elastane makes the structure more compact. From the Figure 6, it can be noticed that as the applied load increases the percentage of stretch ability also increases. From ANOVA analysis it was observed that there is a significant difference in fabric stretch properties of the five denim fabrics having different Lycra percentage $(\mathrm{F}=194.333$, $\mathrm{p}=0.000)$ (Figure 6).

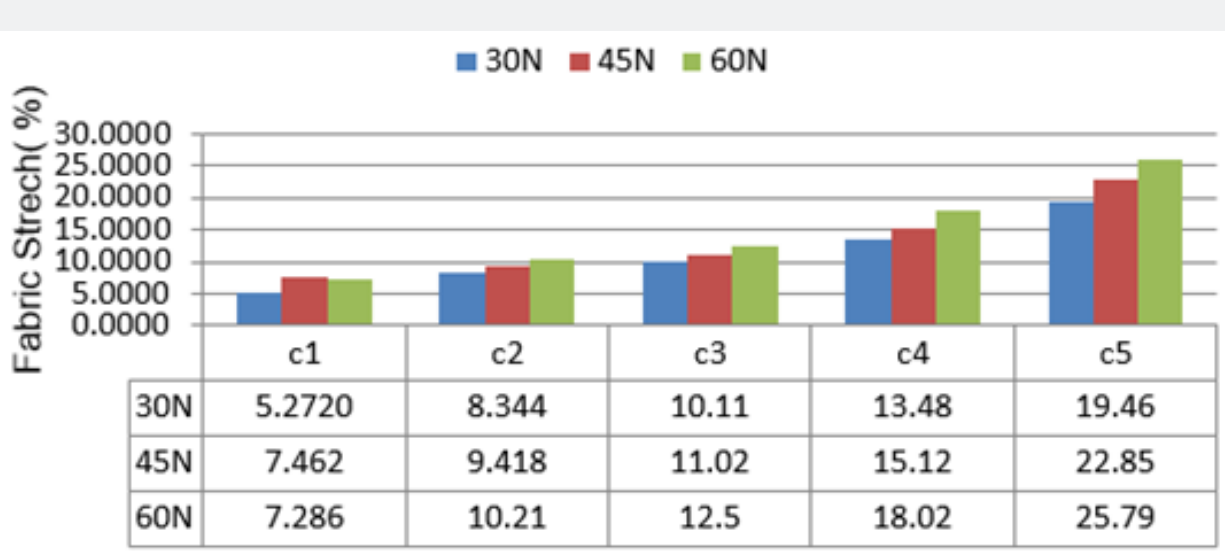

Fabric Code

Figure 6: Stretch ability of denim fabrics at different spandex percentage. 


\section{Current Trends in Fashion Technology \& Textile Engineering}

Table 11: ANOVA table for fabric stretch property.

\begin{tabular}{|c|c|c|c|c|}
\hline & Sum of Squares & Df & Mean Square & F \\
\hline Between Groups & 2360.046 & 4 & 590.012 & 194.333 \\
\hline Within Groups & 212.526 & 70 & 3.036 & 0 \\
\hline Total & 2572.572 & 74 & & \\
\hline
\end{tabular}

\section{Fabric Growth}

Table 12 According to ANOVA statistical analyses the significant effect of spandex percentage on fabric growth were studied and proved that a negative relation between spandex percentage and fabric growth were detected at significance level of $(\mathrm{F}=43.54, \mathrm{p}=0.000)$. The figure assuring that as the spandex percentage increases the fabric growth decreases due to the rather high recovery properties of elastane. The inversely effect of spandex percentage on fabric growth can be attributed to the higher extensibility ranges of the elastic complex yarn, which associated with higher spandex amount. The reduction of fabric growth can be showed in a good fit of fabrics containing spandex (Figure 7).

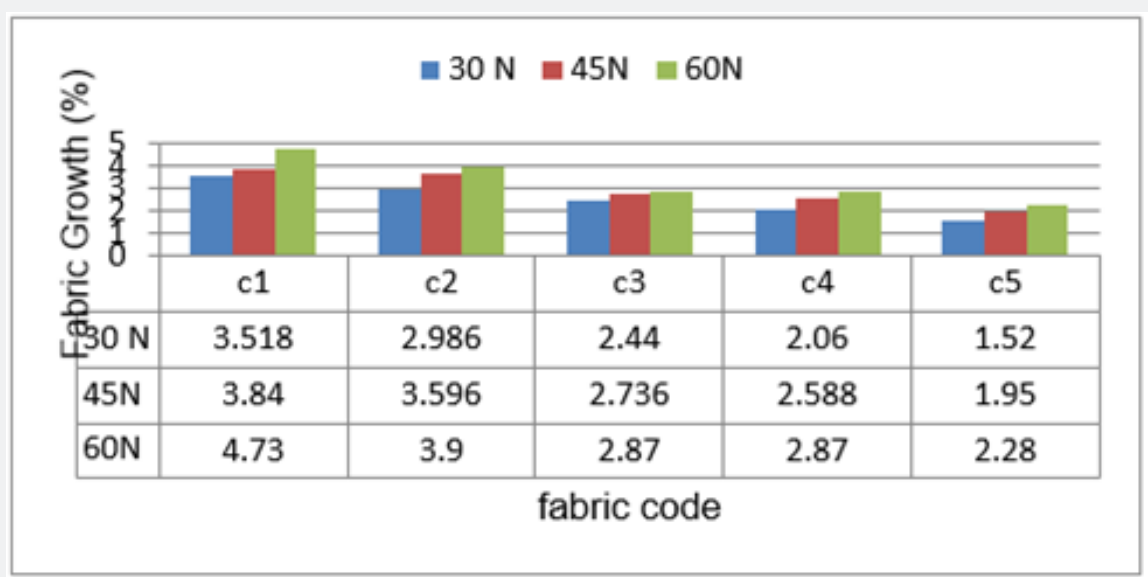

Figure 7: Fabric growth of denim fabrics at different spandex percentage.

Table 12: ANOVA table of fabric growth.

\begin{tabular}{|c|c|c|c|c|c|}
\hline & Sum of Squares & Df & Mean Square & F & Sig. \\
\hline Between Groups & 41.278 & 4 & 10.32 & 0 \\
\hline Within Groups & 16.589 & 70 & 0.237 & \\
\hline Total & 57.867 & 74 & & \\
\hline
\end{tabular}

\section{Elastic recovery}

Table 13 According to the results given in Figure 8, it can be said that there is a positive relation between spandex percentage and elastic recovery. It can be observed that there is a tendency of increasing in elastic recovery values for all fabric samples in proportion to the increase of spandex percentage. These results were to be expected because the spandex in the yarn behaves like a spring, which tends to return to its original length after stretching. From ANOVA analysis it was observed that there is a significant difference in fabric recovery properties of the five denim fabrics having different Lycra percentage $(F=144.523, p=0.000)$ (Figure 8).

Table 13: ANOVA table of fabric elastic recovery.

\begin{tabular}{|c|c|c|c|c|}
\hline & Sum of Squares & df & Mean Square & Fig. \\
\hline Between Groups & 4006.822 & 4 & 1001.706 & 0 \\
\hline Within Groups & 485.177 & 70 & 6.931 & 144.523 \\
\hline Total & 4491.999 & 74 & & \\
\hline
\end{tabular}




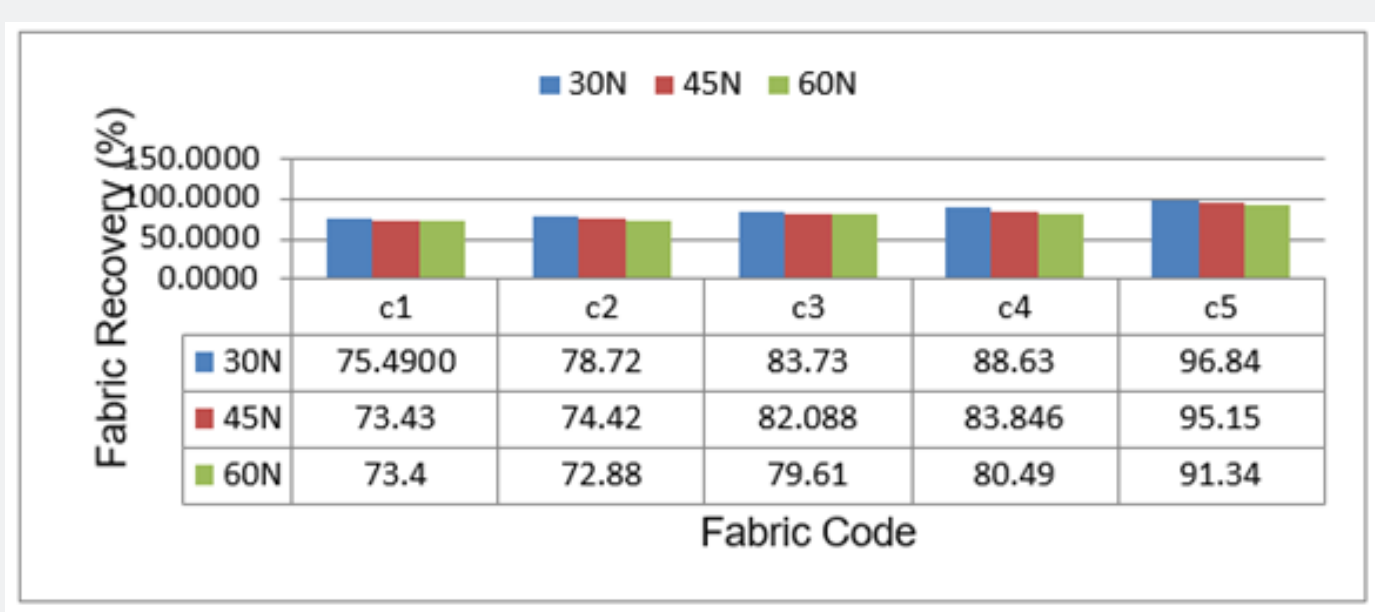

Figure 8: Fabric recovery of denim fabrics at different spandex percentage.

\section{Fabric serviceability property}

\section{Abrasion resistance}

Table 14 Abrasion property of different fabric samples were investigated via different spandex percentage. The statistical analysis proved that the abrasion properties of fabric samples were significantly affected by the percentage of spandex at significance level $\mathrm{P}=0.009$. As seen from Figure 9, the fabric abrasion property increases with the increase in spandex percentage meaning that as the spandex percentage increases the abrasion property of the denim fabric decreases. This is because spandex is more resistant to abrasion than cotton fiber. Long fibers incorporated into fabric confer better abrasion resistance because they are harder to remove from yarn (Figure 9).

Table 14: ANOVA table for abrasion resistance.

\begin{tabular}{|c|c|c|c|c|c|}
\hline & Sum of Squares & Df & Mean Square & F & 4.524 \\
\hline Between Groups & 7.6 & 4 & 1.9 & & 0.009 \\
\hline Within Groups & 8.4 & 20 & 0.42 & & \\
\hline Total & 16 & 24 & & \\
\hline
\end{tabular}

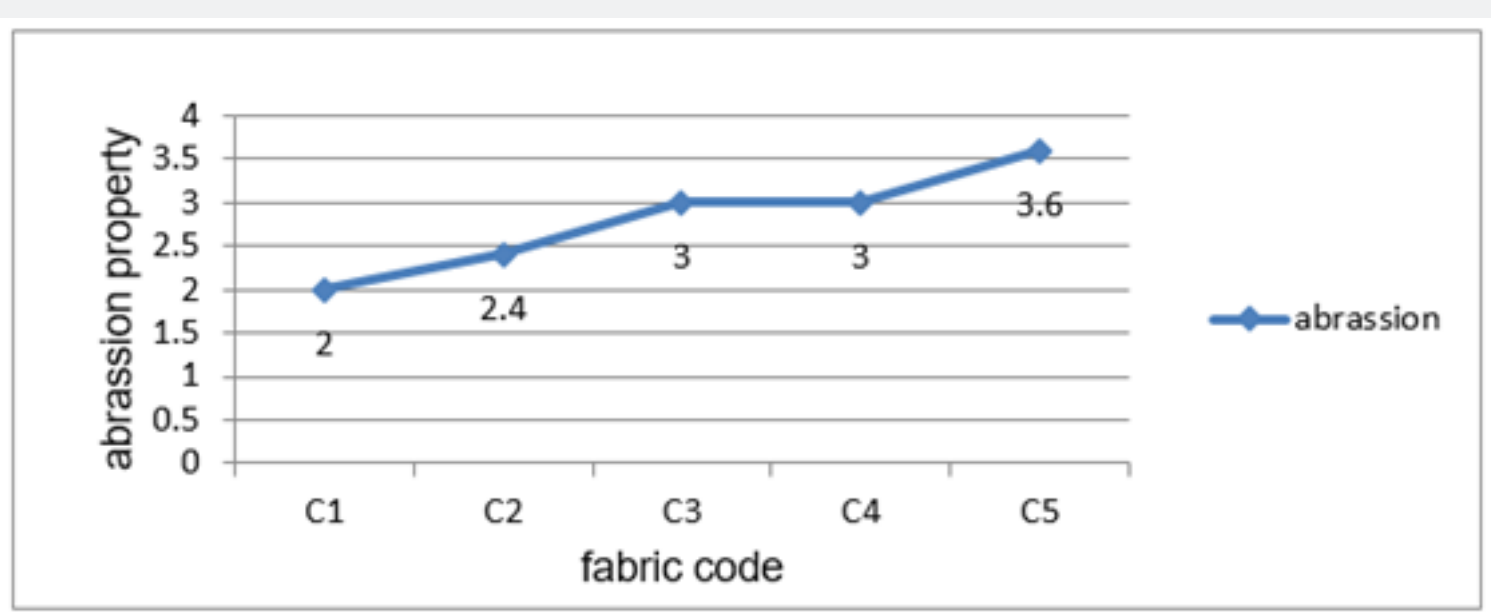

Figure 9: Shows the effect of elastane percentage on fabric abrasion property. 


\section{Pilling property}

Table 15 \& Figure 10 illustrates the relationship between the amount of elastane percentage and the pilling rating for the tested samples produced from 3/1 twill denim fabric at five different variations. From the statistical analysis of pilling rate, it is clearly seen that amount of elastane percentage has a significance effect on pilling rating for all tested fabrics. As percentage of elastane increase the pilling rate increases, because the greater amount of Lycra the tighter the fabric (Figure 10).

Table 15: ANOVA table for pilling rate.

\begin{tabular}{|c|c|c|c|c|}
\hline & Sum of Squares & Df & Mean Square & F \\
\hline Between Groups & 6.16 & 4 & 1.54 & 0.38 \\
\hline Within Groups & 7.6 & 20 & & \\
\hline Total & 13.76 & 24 & \\
\hline
\end{tabular}

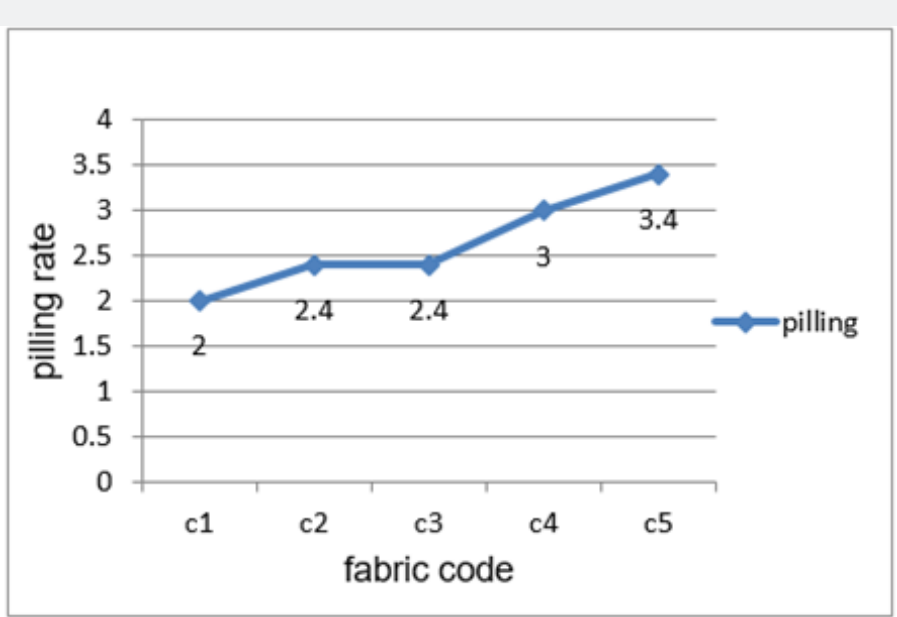

Figure 10: Shows the effect of elastane percentage on fabric pilling.

\section{Conclusion}

The results obtained in the study work Indicates that percentage of elastane has a significant effect on the mechanical and comfort properties of cotton/elastane woven denim fabric. It is observed that tensile strength of denim fabric decreases as the percentage of the elastane increases since the lower tenacity of spandex fibers compared to cotton fibers. Fabric breaking elongation increases as spandex percentage increases; this is because the breaking elongation of spandex fibers was higher than that of cotton fibers. The tear strength of denim fabric decreases as elastane percentage increases. Air permeability performance of the denim fabric decreases as spandex percentage increase since less space for the passage of air. As spandex percentage increased the fabric contraction of the woven fabric were more, which made the fabric more compact, bulk and thicker, resulting in higher resistance to air flow. Hence, the higher amount of spandex content can help in achieving higher stretch ability, with reduced air permeability.

Drape ability of the denim fabric increases as spandex percentage increases. Fabric stretch ability and fabric elastic recovery increases with spandex percentage sine elastane has higher stretch and makes the structure more compact, but fabric growth decreases as spandex percentage increases due to the rather high recovery properties of spandex. It is also apparent that the abrasion and pilling resistance of the denim fabric becomes good as spandex percentage increases because of spandex is more resistant to abrasion than cotton fiber and the greater percentage of spandex the tighter the fabric. In general, tensile strength, tear strength and air permeability are higher at low elastane percentage while breaking elongation, drape ability, fabric stretch properties, abrasion and pilling are good at higher elastane percentage. Statistical analysis proved that the difference between the results for the five fabric were significant for all the properties. Comparing the fabrics analyzed, it can be concluded that they have a wider field of variation in performance characteristics (mechanical \& comfort) of denim fabric as the percentage of elastane content in the yarn starts to change.

\section{References}

1. Mona MA, Haji (2013) Physical and Mechanical Properties of Cotton/ Spandex Fabrics, Indian textile journal.

2. Ambedkar BR (2011) Influences of Elastane Content, Aesthetic Finishes and Fabric Weight on Mechanical and Comfort Properties of Denim Fabrics. Indian Journal of Fibre \& Textile Research 36: 300-307. 
3. Zhang Z, Li Y, Gong C, Wu H (2002) Casual wear product attributes: A Chinese consumers perspective. Journal of Fashion Marketing and Management 6(1): 53-62.

4. Osmud Rahman (2011) Understanding Consumers Perceptions and Behaviors: Implications for Denim Jeans Design. Journal of textile and apparal, technology and management 7(1).

5. Senthilkumar M, Anbumani N, Hayavadana J (2011) Elastane fabrics - A tool for stretch applications in sports. Indian Journal of Fibre and Textile Research 36: 300-307.

6. DuPont de Nemours (1999) Composite yarns with Lycra for weaving Technical Bulletin. L118.

7. Og ulata SN, S ahin C, Ogulata RT ( 2006) The prediction of elongation and recovery of woven bi-stretch fabric using artificial neural network and linear regression models. Fibres Text East Eur 56: 46-49.

8. Baghaei B, Shanbeh M and Ghareaghaji AA (2010) Effect of tensile fatigue cyclic loads on bagging deformation of elastic woven fabric. Indian J Fibre Text Res 35: 298-302.

9. Das A, Chakraborty R (2013) Studies on elastane cotton core spun stretch yarns and fabrics: part 2 fabric low stress mechanical characteristics. Indian journal of fiber \& textile research 38: 340-348.
10. Muhammad Bilal Qadir, Mumtaz Hasan Malik, Tanveer Hussain (2014) ASTM D6554 - 00, Standard performance specification for $100 \%$ cotton denim fabrics. Effect of Elastane Denier and Draft Ratio of Core-Spun Cotton Weft Yarns on the Mechanical Properties of Woven Fabrics. Journal of engineered fibers and fabrics.

11. Ibrahim SM (1966) Mechanisms of stretch development in fabrics containing spandex yarns. Textile research journal 36(8).

12. ASTM D5035 (2019) Textile Strength and Elongation Strip Test.

13. ASTM D1424 - 09 (2013) Standard Test Method for Tearing Strength of Fabrics by Falling-Pendulum (Elmendorf-Type) Apparatus.

14. ASTM D3107 - 07 (2015) Standard Test Methods for Stretch Properties of Fabrics Woven from Stretch Yarns.

15. ASTM D4966 - 12 (2016) Standard Test Method for Abrasion Resistance of Textile Fabrics (Martindale Abrasion Tester Method).

16. ASTM D 737-04 (2016) Standard Test Method for Air Permeability of Textile Fabrics.

17. ASTM D3107-07 (2015) Standard Test Methods for Stretch Properties of Fabrics Woven from Stretch Yarns.

18. ASTM D4970 (2016) Standard Test Method for Pilling Resistance and Other Related Surface Changes of Textile Fabrics: Martindale Tester.

\begin{tabular}{l} 
Your next submission with Juniper Publishers \\
will reach you the below assets \\
- Quality Editorial service \\
- Swift Peer Review \\
- Reprints availability \\
- E-prints Service \\
- Manuscript Podcast for convenient understanding \\
- Global attainment for your research \\
- Manuscript accessibility in different formats \\
( Pdf, E-pub, Full Text, Audio) \\
- Unceasing customer service \\
Track the below URL for one-step submission \\
https://juniperpublishers.com/online-submission.php \\
\hline
\end{tabular}

